\title{
Effectiveness of salivary stimulation using xylitol-malic acid tablets as coadjuvant treatment in patients with gastro-oesophageal reflux disease: early findings
}

\author{
Irene Sánchez-Blanco ${ }^{1}$, Manuel Rodríguez-Téllez ${ }^{2}$, José Ramón Corcuera-Flores ${ }^{1}$, Carolina González-Blanco \\ ${ }^{3}$, Daniel Torres-Lagares ${ }^{4}$, María Ángeles Serrera-Figallo ${ }^{5}$, Guillermo Machuca-Portillo ${ }^{4}$
}

${ }^{1}$ Associate Professor. Master Program of Special Care in Dentistry. University of Seville, Spain

${ }^{2}$ Associate Professor of Gastroenterology. Department of Internal Medicine. University of Seville, Spain

${ }^{3}$ Associate Professor. Master Program of Oral Surgery. University of Seville, Spain

${ }^{4}$ Full Professor. Department of Stomatology. University of Seville, Spain

${ }^{5}$ Associate Professor of Special Care in Dentistry. Department of Stomatology. University of Seville, Spain

Correspondence:

Department of Stomatology

Faculty of Odontology, University of Seville

c/Avicena s/n. 41009-Seville, Spain

gmachuca@us.es

Sánchez-Blanco I, Rodríguez-Téllez M, Corcuera-Flores JR,

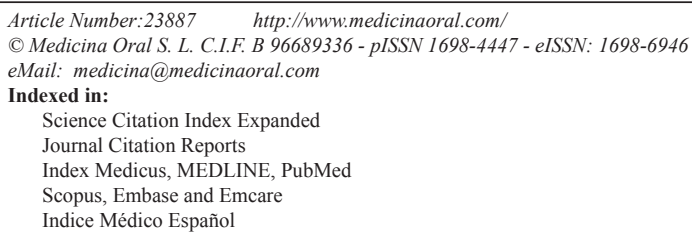

\begin{abstract}
Background: Besides dental erosion syndrome, other oral syndromes could benefit from the stimulation of salivary secretion, in patients with gastro-oesophageal reflux disease (GORD). Our aims is evaluate the improvement of oral extra-oesophageal manifestations in patients with GORD using xylitol-malic acid tablets to stimulate salivary secretion.

Material and Methods: The effectiveness of salivary stimulation using xylitol-malic acid tablets (as a supplement to omeprazole $40 \mathrm{mg} /$ day) was assessed in a clinical trial $(\mathrm{n}=14)$ lasting six months with patients with prior positive $\mathrm{pH}$-metry, through GORD extra-oesophageal clinical signs, GerdQ and RDQ questionnaires, odontological variables, basal salivary secretion, stimulated salivary secretion, $\mathrm{pH}$ and buffer capacity, mucosal erythema index and dental wear. Statistics: chi-square (Haberman post-hoc), ANOVA, and Mann-Whitney U; variables between visits were evaluated with McNemar's Student's t and Wilcoxon tests; $p<0.05$.

Results: $100 \%$ of patients not taking xylitol-malic acid presented xerostomia, but only $14.3 \%$ of patients taking xylitol-malic acid $(p<0.01)$ did. The mean saliva-buffer capacity at the last visit for patients not taking xylitolmalic acid was $2.14 \pm 0.38$, versus $2.71 \pm 0.49$ for patients taking xylitol-malic acid $(p<0.05)$. Retro-sternal burning $(p<0.05)$, heartburn $(p<0.05)$ and regurgitation $(p<0.05)$ were also reduced.

Conclusions: Xylitol-malic acid tablets improve quality of life among patients with GORD, by reducing dry mouth, increasing saliva buffering and reducing heartburn, retro-sternal burning and regurgitation.
\end{abstract}

Key words: Tooth wear, erosion, gastroesophageal reflux, saliva. 


\section{Introduction}

Gastro-oesophageal reflux disease (GORD) is produced when reflux content from the stomach causes symptoms and/or complications (1). The reflux components that cause the most damage are acid and pepsin, although bile and pancreatic enzymes can also contribute to damage in some patients. GORD may or may not have typical symptoms, and it may manifest in patients with a normal oesophagus or with oesophagitis, but reflux episodes are abnormal in all cases (2).

Regarding the pathogenesis of GORD, many factors interact in different proportions, with the predominant factor varying by patient (e.g., defects in the anti-reflux barrier, defective oesophageal clearance, disorders of oesophageal mucosal resistance, increase in gastric acid secretion, delay in gastric emptying or circumstances in which intra-abdominal pressure increases) $(1,3)$.

The typical reflux syndrome is characterized by the presence of heartburn and/or regurgitation. Heartburn is defined as a burning sensation in the retro-sternal area, while regurgitation is defined as perception in the mouth of or the hypopharynx of a flux from gastric content reflux. Apart from these 2 characteristic symptoms, patients may experience others, such as epigastric pain or difficulty falling asleep (1).

Lifestyle changes highly important from both the patient's and the doctor's perspective. Lifestyle changes can improve reflux symptoms in patients with slight to moderate GORD. Among these changes is diet control; avoiding food that can cause reflux is yet another therapeutic measure (4). Eating favours reflux episodes, eating slowly and going to bed at least 4 hours after meals appear to improve the clinical signs of GORD. Giving up smoking, losing weight, avoiding very tight clothing and raising one's head during sleep are recommended $(5,6)$. Lifestyle changes are often not enough; consequently, other therapeutic measures need to be resorted to (4). A wide range of drugs are aimed at treating gastroesophageal reflux disease, such as alginates (sodium alginate), mucosal barrier protectors (sucralfate), prokinetic agents (metoclopramide, domperidone and cisapride), H2-histamine receptor antagonists (cimetidine, famotidine and ranitidine), proton-pump inhibitors (omeprazole, rabeprazole, pantoprazole, lansoprazole, esomeprazole, dexlansoprazole, and immediate-release omeprazole), TLESR reducers and transient lower oesophageal sphincter (LES) relaxation (baclofen) $(7,8)$.

Laparoscopic Nissen fundoplication is the anti-reflux surgical treatment of choice (9). Surgery is indicated in case of medical therapy failure, an onset of complications derived from GORD such as peptic stenosis (10), intolerance to proton-pump inhibitors or patient preference and the desire for a permanent solution from patients who wish to relieve their symptoms without continuing pharmacological treatment for life (11).
Amongst the extra-oesophageal symptoms of GORD, those relating to the oral cavity take on an important dimension. Although researchers have mainly focussed on hard tissue lesions, some researchers have attempted to establish relationships with other oral manifestations and GORD (12). Amongst these oral manifestations are dental sensitivity, bitter taste (13), a burning sensation in the mouth and pharynx, mouth ulcers (3) and erythema on the palate and uvula $(14,15)$. Few studies have been carried out on GORD's role in tooth decay pathogenesis or periodontal disease, although Katunari (16) and Song et al. (17) detected the presence of pathological gingival changes in patients with GORD.

Other authors have focussed on the repercussions of salivary secretion on the oral state of patients with GORD because salivary secretion is a protective mechanism that helps to clear reflux acid from the oesophagus, thus reducing its harmful capacity on tissue (18). Several authors have studied the introduction of chewing gum into the normal treatment for GORD. Saliva production increases when the salivary gland is stimulated, which can compensate for low oral and oesophageal $\mathrm{pH}$ and prevent acid from reaching distal areas (19).

The aim of this study is to assess the improvement to oral extra-oesophageal manifestations in patients with GORD when using xylitol-malic acid tablets as a coadjuvant for treatment along with omeprazole to stimulate salivary secretion.

\section{Material and Methods}

This study was designed as an open, prospective, randomized pilot study to evaluate the effects of stimulating salivary secretion on oral manifestations in patients with GORD (confirmed using positive result $\mathrm{pH}$-metric tests) (20). The inclusion criteria for the study were as follows: the patient must have at least 16 remaining teeth (including upper front teeth); have no other situations favouring reflux and dental erosions, specifically chronic alcoholism, anorexia or bulimia, or excessive consumption of acid foods; be between 18 and 70 years of age, and not be taking any anti-inflammatory or anticholinergic drugs. The presence or absence of dental erosions was not an exclusion factor.

Patients with GORD were randomly assigned using a random number assignation list (1:1) into two groups, to receive standard treatment of proton pump inhibitors (PPIs) or the experimental treatment of PPIs + salivastimulating tablets. In all cases, double doses of omeprazole $(40 \mathrm{mg}$ ) were administered once a day. This basic treatment was complemented by specific tablets for stimulating salivary secretion, specifically of Xeros Dentaid® (Dentaid, Spain), indicated for treating dry mouth. Each patient received a box of individually packaged Xeros Dentaid ${ }^{\circledR}$ tablets. They had to suck the tablets until completely dissolved 3 times a day after main meals. 
The tablets were used as a coadjuvant treatment for GORD and its manifestations. The tablet being placed in the patient's mouth stimulates salivary secretion, swallowing and, with this, oesophageal clearance. Saliva may protect the oral cavity by diminishing the influx of gastric material, neutralizing acids and creating a protective barrier in the mouth. Xeros Dentaid ${ }^{\circledR}$ tablets are part of a range of products indicated for treating dry mouth. The tablets mainly comprise Xylitol (422.00 $\mathrm{mg}$ ), an alcohol derived from xylose. Its composition includes a small proportion of malic acid $(28.58 \mathrm{mg})$, whose function is to further stimulate saliva flow, and sodium fluoride $(0.58 \mathrm{mg})$. Regular use of xylitol, a substance not fermentable by oral bacteria, has been associated with decreased tooth decay, with lower counts of $\mathrm{S}$. mutans and greater plaque $\mathrm{pH}(21)$.

The patients underwent regular check-ups to assess the progress of their oral parameters, with the final checkup being at six months. Initially, and for comparison between both study groups, the patients' sex and age, medical history, service usage data and dental habits (time and reason for last visit to the dentist, frequency of visits to the dentist, frequency and type of brushing, frequency and type of interdental cleaning, use of mouthwash and use of prosthesis) were recorded.

Extra-oesophageal manifestations of GORD were recorded (chronic cough, laryngitis, pharyngitis, asthma, idiopathic pulmonary fibrosis, sinusitis, recurrent otitis media, chronic hoarseness and chronic bronchitis) at the study's outset and after six months, as were other odontological variables (xerostomia, burning mouth, dysgeusia, basal and stimulated salivary secretion, saliva $\mathrm{pH}$, buffer capacity (by adding $\mathrm{HCl}$, with 1 = low, 2 = medium and $3=$ high), O'Leary's oral hygiene index, plaque index, calculus index, CAOD index, mucosal erythema index (with a score of $0=$ normal, $1=$ slight erythema, $2=$ moderate erythema and $3=$ severe erythema), ulcerations $(0=$ absent, $1=$ ulcers less than $0.25 \mathrm{~cm}$ in diameter and $2=$ ulcers are larger $.25 \mathrm{~cm}$ in diameter) and dental wear (applying Smith and Knight's dental wear index [TWI] (22), with a score of 0 to 4). Validated GerdQ questionnaires were also recorded (with each question scored on a scale of 0 to 3 , with $0=$ no episode in the last week, $1=1$ episode in the last week, 2 = between 2 and 3 episodes in the last week and $3=$ from 4 to 7 episodes in the last week), as was RDQ, scored on 2 dimensions: frequency $(0=$ never, $1=$ less than once per week, 2 = once per week, $3=$ between 2 and 3 times a week, $4=$ from 4 to 6 times a week and $5=$ daily episodes $)$ and intensity $(0=$ no episodes, $1=$ a very slight episode, 2 = a slight episode, $3=$ a moderate episode, $4=$ a moderate to severe episode and $5=$ a severe episode). This study was conducted in accordance with the ethical principles for medical research on humans, as defined in the Declaration of Helsinki, and following the standards of good clinical practice. Approval was obtained from the Ethical Committee of Virgen del Rocío and Virgen Macarena Hospital before commencing the study. Each patient was duly informed and required a signed informed consent form to take part in the study. Statistical analysis was undertaken using the program SPSS 12.0. The Kolmogorov-Smirnov test was used to check for normality of the quantitative variables. Statistical differences between the two groups were compared with qualitative variables using the chi-square test and with the Haberman post-hoc test applied. For numerical variables, analysis of variance (ANOVA) was used when a normal distribution was present, and the MannWhitney U test was used with nonnormal distributions. To evaluate the progress of a variable over the different visits, the McNemar non-parametric test was used on dichotomous variables, Student's t-tests were on numerical variables with normal distributions and the Wilcoxon test was used on numerical variables with nonnormal distributions and on ordinal qualitative variables. Values of $p<0.05$ were deemed statistically significant.

\section{Results}

Fourteen patients with GORD (Table 1) were studied: 10 women and $4 \mathrm{men}$. Of these patients, 9 were younger than 55 years of age ( 5 of these patients took tablets), and 5 patients were over 55 years of age ( 2 took tablets). In total, $7(50 \%)$ took the tablets and 7 (50\%) did not. Regarding the patients' medical history (Table 2), 2 (28.6\%) presented a history of heart failure, $2(28.6 \%)$ presented a history of high blood pressure, 1 (14.3\%) presented thyroid problems and $2(28.6 \%)$ presented other pathologies. Four patients presented anxiety and/ or depression, of whom 1 (7.1\%) was not taking tablets and $3(21.4 \%)$ were taking them.

Table 1: Initial data relating to age and sex in the sample studied.

\begin{tabular}{|c|c|c|c|c|c|}
\hline \multirow{3}{*}{ Sex } & \multicolumn{4}{|c|}{ Use of tablet } & \multirow[b]{3}{*}{ Sign. } \\
\hline & \multicolumn{2}{|c|}{ No } & \multicolumn{2}{|c|}{ Yes } & \\
\hline & Freq. & Perc. & Freq. & Perc. & \\
\hline Woman & 6 & 85.7 & 4 & 57.1 & \\
\hline Man & 1 & 14.3 & 3 & 42.9 & \\
\hline Age & Freq. & Perc. & Freq. & Perc. & Sign. \\
\hline Up to 55 years & 4 & 57.1 & 5 & 71.4 & \\
\hline Over 55 years & 3 & 42.9 & 2 & 28.6 & \\
\hline
\end{tabular}


Table 2: Medical history, oral habits and dental variables in the sample studied.

\begin{tabular}{|c|c|c|c|c|c|c|}
\hline \multicolumn{7}{|c|}{ Use of tablet } \\
\hline \multirow{2}{*}{\multicolumn{2}{|c|}{ ( $\mathrm{n}$ and \% of positive cases) }} & \multicolumn{2}{|c|}{ No } & \multicolumn{2}{|c|}{ Yes } & \multirow[b]{2}{*}{ Sign. } \\
\hline & & Freq. & Perc. & Freq. & Perc. & \\
\hline \multirow{20}{*}{ Medical history } & Angina/ Infarction & 0 & 0.0 & 0 & 0.0 & \\
\hline & Murmur/ Valve & 0 & 0.0 & 0 & 0.0 & \\
\hline & Arrhythmia & 0 & 0.0 & 0 & 0.0 & \\
\hline & Heart failure & 2 & 28.6 & 0 & 0.0 & \\
\hline & High blood pressure & 2 & 28.6 & 1 & 14.3 & \\
\hline & Haemostatic disorder & 0 & 0.0 & 0 & 0.0 & \\
\hline & Cerebral vascular accident & 0 & 0.0 & 0 & 0.0 & \\
\hline & Epilepsy & 0 & 0.0 & 0 & 0.0 & \\
\hline & Asthma & 0 & 0.0 & 0 & 0.0 & \\
\hline & Pulmonary problems or cough & 0 & 0.0 & 0 & 0.0 & \\
\hline & Diabetes & 0 & 0.0 & 0 & 0.0 & \\
\hline & Thyroid & 1 & 14.3 & 1 & 14.3 & \\
\hline & Liver disorder & 0 & 0.0 & 0 & 0.0 & \\
\hline & Intestinal disorder & 0 & 0.0 & 0 & 0.0 & \\
\hline & Kidney disorder & 0 & 0.0 & 0 & 0.0 & \\
\hline & Cancer or leukaemia & 0 & 0.0 & 0 & 0.0 & \\
\hline & Infectious disease & 0 & 0.0 & 0 & 0.0 & \\
\hline & Immune system disorder & 0 & 0.0 & 0 & 0.0 & \\
\hline & Skin disorder & 0 & 0.0 & 0 & 0.0 & \\
\hline & Other diseases & 2 & 28.6 & 2 & 28.6 & \\
\hline \multirow{2}{*}{ Anxiety and/or depression } & No & 5 & 92.9 & 11 & 78.6 & \\
\hline & Yes & 1 & 7.1 & 3 & 21.4 & \\
\hline \multirow{2}{*}{ Taking antihypertensive drugs } & No & 3 & 42.9 & 6 & 85.7 & \\
\hline & Yes & 4 & 57.1 & 1 & 14.3 & \\
\hline \multirow{2}{*}{$\begin{array}{l}\text { Taking anxiolytic - } \\
\text { antidepressants- muscle relaxants }\end{array}$} & No & 5 & 71.4 & 6 & 85.7 & \\
\hline & Yes & 2 & 28.6 & 1 & 14.3 & \\
\hline \multirow{3}{*}{ Time since last visit to the dentist } & Less than one year & 4 & 57.1 & 2 & 28.6 & \\
\hline & Between 1 and 2 years & 2 & 28.6 & 2 & 28.6 & \\
\hline & Two or more years & 1 & 21.4 & 3 & 42.9 & \\
\hline \multirow{5}{*}{ Reason for visiting the dentist } & Check-up & 3 & 42.9 & 2 & 28.6 & \\
\hline & Cleaning & 4 & 57.1 & 2 & 28.6 & \\
\hline & Fillings & 1 & 14.3 & 2 & 28.6 & \\
\hline & Extractions & 2 & 28.6 & 1 & 14.3 & \\
\hline & Other treatment & 1 & 14.3 & 2 & 28.6 & \\
\hline \multirow{2}{*}{ Frequency of dental visits } & On demand & 2 & 28.6 & 4 & 57.1 & \\
\hline & Between 0.5 and 1.5 times / year & 5 & 71.4 & 3 & 42.9 & \\
\hline \multirow{3}{*}{ Brushing frequency (times per day) } & Once & 3 & 42.9 & 2 & 28.6 & \\
\hline & Between 1 and 2 times & 2 & 28.6 & 3 & 42.9 & \\
\hline & More than twice & 2 & 28.6 & 2 & 28.6 & \\
\hline \multirow{2}{*}{ Type of toothbrush } & Manual & 5 & 71.4 & 4 & 57.1 & \\
\hline & Electric (or both) & 2 & 28.6 & 3 & 42.9 & \\
\hline \multirow{2}{*}{ Use of floss or interdental brush } & Yes & 2 & 28.6 & 2 & 28.6 & \\
\hline & No & 5 & 71.4 & 5 & 71.4 & \\
\hline \multirow{2}{*}{$\begin{array}{l}\text { Frequency of use of floss or } \\
\text { interdental brush }\end{array}$} & Daily & 0 & 0.0 & 1 & 100.0 & \\
\hline & Twice or three times / week & 1 & 100.0 & 0 & 0.0 & \\
\hline \multirow{2}{*}{ Use of mouthwash } & Yes & 4 & 57.1 & 2 & 28.6 & \\
\hline & No & 3 & 42.9 & 5 & 57.1 & \\
\hline \multirow{3}{*}{ Frequency of use of mouthwash } & Daily & 3 & 60.0 & 2 & 50.0 & \\
\hline & Once or twice / week & 0 & 0.0 & 2 & 50.0 & \\
\hline & Occasionally & 2 & 40.0 & 0 & 0.0 & \\
\hline Prosthesis ncar & Yes & 3 & 21.4 & 3 & 23.1 & \\
\hline Prosthesis user & No & 11 & 78.6 & 10 & 76.9 & \\
\hline
\end{tabular}


Regarding the time since their last visit to the dentist, among those who had last visited a dentist less than 1 year ago, 4 patients $(57.1 \%)$ were not taking the tablets, and $2(28.6 \%)$ were. For those from whom it had been between and 1 and 2 years since the last visit, 2 (28.6\% of patients) were not taking the tablets, and 3 $(42.9 \%)$ patients were. Regarding the reason for visiting the dentist, the most common one was for scaling and dental prophylaxis, with $4(57.1 \%)$ of these patients not taking the tablets and $2(28.6 \%)$ who were.

The study groups were comparable, in terms of epidemiological and socioeconomic variables, since no significant differences were found.

Regarding the variables studied, the following data were found at the outset. With reference to extraoesophageal manifestations (Table 3), chronic cough was presented by $1(14.3 \%)$ patient who was not taking the tablets and $4(57.1 \%)$ patients who were $(p<0.05)$; with regard to chronic hoarseness, it was presented by $3(42.9 \%)$ patients who were taking the tablets $(p<$ 0.05 ). The emergence of laryngitis, pharyngitis, asthma, pulmonary fibrosis, sinusitis or otitis media had no significant relationship with taking the xylitol-malic acid tablets.

Regarding the dental history variables (Table 3), no significant differences were found between the patients taking xylitol-malic acid and those who were not taking it in terms of the variables identifying the presence of xerostomia, dysgeusia or burning mouth; those referring to $\mathrm{pH}$, basal and stimulated saliva or saliva-buffering capacity; the indices for plaque, calculus, CAOD index or mucosal erythema index; number of ulcers; or tooth wear.

Regarding the GerdQ questionnaire, on average, the results for a burning sensation behind the sternum were $4.00 \pm 0.00$ for the group not taking the tablets and $2.57 \pm 1.27$ for the patients who were taking the tablets $(p<0.05)$. No significant differences were found between the study groups for any of the other aspects contemplated in this index (Table 3).

Regarding the RDQ (Frequency) index, significant differences $(p<0.01)$ between both groups were only found at the start of the study in relation to localized burning behind the sternum $(6.00 \pm 0.00$ for patients not taking the tablets versus $3.75 \pm 2.07$ for those who were), stomach acidity ( $6.00 \pm 0.00$ for patients not taking the tablets versus $3.14 \pm 2.27$ for those who were) $(p<0.01)$ and gastric reflux $(4.00 \pm 2.24$ for patients not taking the tablets versus $1.43 \pm 1.13$ for patients who were) $(p<0.05)$ (Table 3$)$.

In relation to the RDQ (Intensity) index, the 2 groups only had significant differences $(p<0.01)$ in connection with burning behind the sternum $(5.29 \pm 0.76$ for patients not taking the tablets versus $3.43 \pm 2.07$ for those who were), stomach acidity (5.29 \pm 0.76 in patients not taking the tablets versus $2.71 \pm 1.89$ for those who were taking xylitol-malic acid) $(p<0.01)$ and gastric reflux $(3.29 \pm 2.14$ in patients not taking the tablets versus $1.57 \pm 1.51$ in those who were taking xylitol-malic acid) $(p<0.05)$ (Table 3$)$.

Between the first and last visit, after 6 months, both groups had similar initial values for their socioeconomic aspects and medical and odontological history. Significant differences were only found in some values for GerdQ and RDQ. Notwithstanding, this difference justified why the analysis of both groups regarding the studied values should not be carried against each the other; rather, we focused on the improvement in each group, taking as the first-visit values as the reference point.

No significant differences between the patients taking the xylitol-malic acid tablets and the patients not taking them were established with respect to the majority of the studied variables, when the first-visit data were compared with the final-visit data (Table 4). No significant differences were found after 6 months in the extra-oesophageal or dental history manifestations, the CAOD index evaluation, the dental wear evaluation or the mucosal erythema index. Regarding saliva analysis, the group that did take the xylitol-malic acid tablets had increased buffer capacity (up to $2.71 \pm 0.49$ from values starting at $2.17 \pm 0.41$ ), a statistically significant difference $(p<0.05)$, while the group that did not take the tablets did not obtain any improvement in this parameter.

Regarding the GerdQ and RDQ questionnaires (Table 4), several symptoms showed improvements. The improvement to the burning sensation behind the sternum (GErdQ) was similar between the 2 groups, at the same percentage. At the end of the study, the group not taking the tablets presented a mean of $50 \%$ of the firstvisit value for this value, compared with $50.19 \%$ for the group taking the tablets ( $p<0.05$ in both cases). Regarding the same sensation but measured with RDQ (Frequency) and RDQ (Intensity), the improvement in both groups was similar in both groups and statistically significant $(p<0.05)$. On the RDQ (Frequency) measurement, the mean value at week 3 was $42.83 \%$ of the initial one for the group not taking the tablets, versus $40.05 \%$ for the other group. Similar improvement percentages were obtained on the RDQ (Intensity) for the same variable $(p<0.05)$.

The results for the stomach acidity variable in the RDQ (Frequency) and RDQ (Intensity) behaved similarly. Both study groups showed statistically significant improvements, with a similar intensity, when comparing data from the first and final visits $(p<0.05)$. The rest of the variables did not present any statistically significant differences between the first- and last-visit values (Table 4). 
Table 3: Extra-oesophageal manifestations.

\begin{tabular}{|c|c|c|c|c|c|c|}
\hline \multicolumn{7}{|c|}{ Use of tablet } \\
\hline \multirow{2}{*}{\multicolumn{2}{|c|}{ ( $n$ and $\%$ of positive cases) }} & \multicolumn{2}{|c|}{ No } & \multicolumn{2}{|c|}{ Yes } & \multirow{3}{*}{$\begin{array}{l}\text { Sign. } \\
\text { Quasi }\end{array}$} \\
\hline & & \multirow{2}{*}{$\begin{array}{c}\text { Freq. } \\
1\end{array}$} & \multirow{2}{*}{$\frac{\text { Perc. }}{14.3}$} & \multirow{2}{*}{$\frac{\text { Freq. }}{4}$} & \multirow{2}{*}{$\begin{array}{ll}\text { Perc. } \\
57.1 \\
\end{array}$} & \\
\hline \multirow{9}{*}{ Extra-oesophageal manifestations } & Chronic cough & & & & & \\
\hline & Laryngitis & 1 & 14.3 & 2 & 28.6 & \\
\hline & Pharyngitis & 2 & 28.6 & 3 & 42.9 & \\
\hline & Asthma & 1 & 14.3 & 1 & 14.3 & \\
\hline & Idiopathic pulmonary fibrosis & 0 & 0.0 & 0 & 0.0 & \\
\hline & Sinusitis & 0 & 0.0 & 0 & 0.0 & \\
\hline & Recurrent otitis media & 0 & 0.0 & 0 & 0.0 & \\
\hline & Chronic hoarseness & 0 & 0.0 & 3 & 42.9 & Quasi \\
\hline & Chronic bronchitis & 0 & 0.0 & 1 & 14.3 & \\
\hline \multirow{3}{*}{ Dental history } & Xerostomia & 6 & 85.7 & 4 & 57.1 & \\
\hline & Burning mouth & 2 & 21.4 & 2 & 21.4 & \\
\hline & Dysgeusia & 2 & 21.4 & 2 & 21.4 & \\
\hline \multirow{5}{*}{ Saliva and pH } & Basal saliva $(\mathrm{ml})$ & 2.06 & 1.42 & 3.33 & 1.18 & \\
\hline & Stimulated saliva $(\mathrm{ml})$ & 6.70 & 3.13 & 8.30 & 3.81 & \\
\hline & $\mathrm{pH}$ basal saliva & 6.71 & 0.27 & 6.83 & 0.26 & \\
\hline & $\mathrm{pH}$ stimulated saliva & 7.00 & 0.00 & 7.08 & 0.20 & \\
\hline & Saliva buffering capacity & 2.14 & 0.38 & 2.17 & 0.41 & \\
\hline \multirow{2}{*}{$\begin{array}{l}\text { O'Leary oral hygiene index and } \\
\text { calculus index }\end{array}$} & Plaque index & 1.43 & 0.53 & 1.57 & 0.79 & \\
\hline & Calculus index & 1.00 & 1.00 & 0.71 & 1.11 & \\
\hline \multirow{5}{*}{ CAOD index and associated variables } & Caries & 0.71 & 1.25 & 1.86 & 1.35 & Quasi \\
\hline & Missing & 6.29 & 3.99 & 3.57 & 3.46 & \\
\hline & Filled & 4.57 & 6.83 & 6.57 & 3.55 & \\
\hline & Teeth & 21.71 & 3.99 & 24.43 & 3.46 & \\
\hline & CAOD index & 0.41 & 0.22 & 0.43 & 0.19 & \\
\hline \multirow{3}{*}{ Mucosal erythema index and ulcers } & Uvula & 1.14 & 0.90 & 1.57 & 0.79 & \\
\hline & Soft palate & 0.57 & 0.79 & 1.00 & 0.82 & \\
\hline & Ulcerations & 0.00 & 0.00 & 0.29 & 0.76 & \\
\hline \multirow{3}{*}{ Tooth wear } & Mean incisor wear & 2.43 & 1.27 & 2.86 & 0.90 & \\
\hline & Mean canine wear & 1.86 & 0.38 & 1.86 & 0.69 & \\
\hline & Mean premolar and molar wear & 1.43 & 1.90 & 2.14 & 1.86 & \\
\hline \multirow{6}{*}{ GerdQ } & Burning sensation behind sternum & 4.00 & 0.00 & 2.57 & 1.27 & $<0.05$ \\
\hline & Stomach content reflux & 2.86 & 1.35 & 1.86 & 1.46 & \\
\hline & Stomach-ache & 1.86 & 1.46 & 1.43 & 1.13 & \\
\hline & Has had nausea & 2.14 & 1.46 & 2.00 & 1.41 & \\
\hline & Sleep difficulties & 2.29 & 1.60 & 1.14 & 0.38 & \\
\hline & Additional medication for burning & 1.60 & 1.34 & 1.00 & 0.00 & \\
\hline \multirow{6}{*}{ RDQ (Frequency) } & Burning behind sternum & 6.00 & 0.00 & 3.57 & 2.07 & $<0.01$ \\
\hline & Pain behind sternum & 1.71 & 1.89 & 1.00 & 0.00 & \\
\hline & Burning in stomach & 6.00 & 0.00 & 3.14 & 2.27 & $<0.01$ \\
\hline & Stomach-ache & 2.43 & 2.44 & 1.00 & 0.00 & \\
\hline & Bitter taste in mouth & 3.71 & 2.56 & 2.43 & 2.44 & \\
\hline & Stomach content reflux & 4.00 & 2.24 & 1.43 & 1.13 & $<0.05$ \\
\hline \multirow{6}{*}{ RDQ (Intensity) } & Burning behind sternum & 5.29 & 0.76 & 3.43 & 2.07 & $<0.01$ \\
\hline & Pain behind sternum & 1.57 & 1.51 & 1.00 & 0.00 & \\
\hline & Burning in stomach & 5.29 & 0.76 & 2.71 & 1.89 & $<0.01$ \\
\hline & Stomach-ache & 2.14 & 1.95 & 1.00 & 0.00 & \\
\hline & Bitter taste in mouth & 3.29 & 2.21 & 1.71 & 1.25 & \\
\hline & Stomach content reflux & 3.29 & 2.14 & 1.57 & 1.51 & Quasi \\
\hline
\end{tabular}


Table 4: Comparison of variables between first and last visit in study groups.

\begin{tabular}{|c|c|c|c|c|c|c|c|}
\hline \multirow{2}{*}{\multicolumn{2}{|c|}{ (\% of positive cases) }} & \multicolumn{3}{|c|}{ Without tablets } & \multicolumn{3}{|c|}{ With tablets } \\
\hline & & \multirow{2}{*}{$\begin{array}{c}\text { Last visit } \\
14.3\end{array}$} & \multirow{2}{*}{$\begin{array}{c}\text { First visit } \\
14.3\end{array}$} & \multirow[t]{2}{*}{ Sig. } & \multirow{2}{*}{$\begin{array}{c}\text { Last visit } \\
57.1\end{array}$} & \multirow{2}{*}{$\begin{array}{c}\text { First visit } \\
57.1\end{array}$} & \multirow{2}{*}{ Sig. } \\
\hline \multirow{9}{*}{$\begin{array}{l}\text { Extra-oesophageal } \\
\text { manifestations }\end{array}$} & Chronic cough & & & & & & \\
\hline & Laryngitis & 0.0 & 14.3 & & 28.6 & 28.6 & \\
\hline & Pharyngitis & 14.3 & 28.6 & & 42.9 & 42.9 & \\
\hline & Asthma & 0.0 & 14.3 & & 14.3 & 14.3 & \\
\hline & Idiopathic pulmonary fibrosis & 0.0 & 0.0 & & 0.0 & 0.0 & \\
\hline & Sinusitis & 0.0 & 0.0 & & 0.0 & 0.0 & \\
\hline & Recurrent otitis media & 0.0 & 0.0 & & 0.0 & 0.0 & \\
\hline & Chronic hoarseness & 0.0 & 0.0 & & 57.1 & 42.9 & \\
\hline & Chronic bronchitis & 0.0 & 0.0 & & 14.3 & 14.3 & \\
\hline \multirow{3}{*}{ Dental history } & Xerostomia & 100.0 & 85.7 & & 14.3 & 57.1 & \\
\hline & Burning mouth & 14.3 & 28.6 & & 0.0 & 0.0 & \\
\hline & Dysgeusia & 12.5 & 28.6 & & 0.0 & 0.0 & \\
\hline \multirow{5}{*}{ Saliva and pH } & Basal saliva (ml) & $2.49 \pm 1.68$ & $2.06 \pm 1.42$ & & $4.09 \pm 1.08$ & $3.33 \pm 1.18$ & \\
\hline & Stimulated saliva (ml) & $7.31 \pm 4.33$ & $6.70 \pm 3.13$ & & $8.99 \pm 4.05$ & $8.30 \pm 3.81$ & \\
\hline & pH basal saliva & $6.79 \pm 0.27$ & $6.71 \pm 0.27$ & & $7.00 \pm 0.00$ & $6.83 \pm 0.26$ & \\
\hline & $\mathrm{pH}$ stimulated saliva & $7.07 \pm 0.19$ & $7.00 \pm 0.00$ & & $7.21 \pm 0.27$ & $7.08 \pm 0.20$ & \\
\hline & Saliva buffering capacity & $2.14 \pm 0.38$ & $2.14 \pm 0.38$ & & $2.71 \pm 0.49$ & $2.17 \pm 0.41$ & $<0.05$ \\
\hline \multirow{2}{*}{$\begin{array}{l}\text { O'Leary oral hy- } \\
\text { giene index and } \\
\text { calculus index }\end{array}$} & Plaque index & $1.43 \pm 0.53$ & $1.43 \pm 0.53$ & & $1.14 \pm 1.07$ & $1.57 \pm 0.79$ & \\
\hline & Calculus index & $0.71 \pm 0.83$ & $1.00 \pm 1.00$ & & $0.71 \pm 0.76$ & $0.71 \pm 1.11$ & \\
\hline \multirow{5}{*}{$\begin{array}{l}\text { CAOD index and } \\
\text { associated varia- } \\
\text { bles }\end{array}$} & Caries & $0.86 \pm 1.22$ & $0.71 \pm 1.25$ & & $2.00 \pm 1.53$ & $1.86 \pm 1.35$ & \\
\hline & Missing & $6.71 \pm 4.89$ & $6.29 \pm 3.99$ & & $3.71 \pm 3.59$ & $3.57 \pm 3.46$ & \\
\hline & Filled & $4.57 \pm 6.83$ & $4.57 \pm 6.83$ & & $6.57 \pm 3.55$ & $6.57 \pm 3.55$ & \\
\hline & Teeth & $21.71 \pm 3.99$ & $21.71 \pm 3.99$ & & $24.43 \pm 3.46$ & $24.43 \pm 3.46$ & \\
\hline & CAOD index & $0.42 \pm 0.23$ & $0.41 \pm 0.22$ & & $0.44 \pm 0.20$ & $0.43 \pm 0.19$ & \\
\hline \multirow{3}{*}{$\begin{array}{l}\text { Mucosal erythema } \\
\text { index and ulcers }\end{array}$} & Uvula & $1.00 \pm 0.58$ & $1.14 \pm 0.90$ & & $1.00 \pm 0.58$ & $1.57 \pm 0.79$ & \\
\hline & Soft palate & $0.00 \pm 0.00$ & $0.57 \pm 0.79$ & & $0.71 \pm 0.76$ & $1.00 \pm 0.82$ & \\
\hline & Ulcerations & $0.00 \pm 0.00$ & $0.00 \pm 0.00$ & & $0.14 \pm 0.38$ & $0.29 \pm 0.76$ & \\
\hline \multirow{3}{*}{ Tooth wear } & Mean incisor wear & $2.86 \pm 1.46$ & $2.43 \pm 1.27$ & & $2.71 \pm 0.95$ & $2.86 \pm 0.90$ & \\
\hline & Mean canine wear & $2.00 \pm 1.29$ & $1.86 \pm 0.38$ & & $1.71 \pm 1.11$ & $1.86 \pm 0.69$ & \\
\hline & Mean premolar and molar wear & $1.14 \pm 1.95$ & $1.43 \pm 1.90$ & & $2.00 \pm 2.00$ & $2.14 \pm 1.86$ & \\
\hline \multirow{6}{*}{ GerdQ } & Burning sensation behind sternum & $2.00 \pm 1.41$ & $4.00 \pm 0.00$ & $<0.05$ & $1.29 \pm 0.76$ & $2.57 \pm 1.27$ & $<0.05$ \\
\hline & Stomach content reflux & $1.86 \pm 1.22$ & $2.86 \pm 1.35$ & & $1.57 \pm 1.13$ & $1.86 \pm 1.46$ & \\
\hline & Stomach-ache & $1.86 \pm 1.46$ & $1.86 \pm 1.46$ & & $1.14 \pm 0.38$ & $1.43 \pm 1.13$ & \\
\hline & Has had nausea & $2.00 \pm 1.29$ & $2.14 \pm 1.46$ & & $1.57 \pm 1.13$ & $2.00 \pm 1.41$ & \\
\hline & Sleep difficulties & $1.43 \pm 0.79$ & $2.29 \pm 1.60$ & & $1.14 \pm 0.38$ & $1.14 \pm 0.38$ & \\
\hline & Additional medication for burning & $1.71 \pm 1.25$ & $1.60 \pm 1.34$ & & $1.00 \pm 0.00$ & $1.00 \pm 0.00$ & \\
\hline \multirow{6}{*}{ RDQ (Frequency) } & Burning behind sternum & $2.57 \pm 2.15$ & $6.00 \pm 0.00$ & $<0.05$ & $1.43 \pm 1.13$ & $3.57 \pm 2.07$ & $<0.05$ \\
\hline & Pain behind sternum & $1.00 \pm 0.00$ & $1.71 \pm 1.89$ & & $1.00 \pm 0.00$ & $1.00 \pm 0.00$ & \\
\hline & Burning in stomach & $2.29 \pm 1.21$ & $6.00 \pm 0.00$ & $<0.05$ & $1.43 \pm 1.13$ & $3.14 \pm 2.27$ & $<0.05$ \\
\hline & Stomach-ache & $2.29 \pm 2.21$ & $2.43 \pm 2.44$ & & $1.43 \pm 1.13$ & $1.00 \pm 0.00$ & \\
\hline & Bitter taste in mouth & $3.00 \pm 2.24$ & $3.71 \pm 2.56$ & & $1.00 \pm 0.00$ & $2.43 \pm 2.44$ & \\
\hline & Stomach content reflux & $2.43 \pm 1.99$ & $4.00 \pm 2.24$ & & $1.71 \pm 1.89$ & $1.43 \pm 1.13$ & \\
\hline \multirow{6}{*}{ RDQ (Intensity) } & Burning behind sternum & $2.29 \pm 1.89$ & $5.29 \pm 0.76$ & $<0.05$ & $1.29 \pm 0.76$ & $3.43 \pm 2.07$ & $<0.05$ \\
\hline & Pain behind sternum & $1.00 \pm 0.00$ & $1.57 \pm 1.51$ & & $1.00 \pm 0.00$ & $1.00 \pm 0.00$ & \\
\hline & Burning in stomach & $2.00 \pm 1.91$ & $5.29 \pm 0.76$ & $<0.05$ & $1.29 \pm 0.76$ & $2.71 \pm 1.89$ & $<0.05$ \\
\hline & Stomach-ache & $1.86 \pm 1.86$ & $2.14 \pm 1.95$ & & $1.00 \pm 0.00$ & $1.00 \pm 0.00$ & \\
\hline & Bitter taste in mouth & $3.00 \pm 2.24$ & $3.29 \pm 2.21$ & & $1.00 \pm 0.00$ & $1.71 \pm 1.25$ & \\
\hline & Stomach content reflux & $2.86 \pm 2.41$ & $3.29 \pm 2.14$ & & $1.71 \pm 1.25$ & $1.57 \pm 1.51$ & \\
\hline
\end{tabular}




\section{Discussion}

The two groups had significant differences in terms of the xerostomia variable. Upon completing the study, all of the patients in the control group (100\%) stated that they had suffered xerostomia, compared to only $2(14.3 \%)$ in the group taking the tablets. This finding implies that consumption of chewable tablets increases salivary secretion.

Lapiedra et al. (23) reached the same conclusion in a study on 34 patients who were divided into 2 groups; 1 group was administered saliva-stimulating tablets containing xylitol, and the other control group was provided sorbitol tablets for 1 week. After resting for 1 week, the groups were inverted, with the study group receiving sorbitol tablets and vice versa. In this study, xerostomia was measured using a subjective questionnaire, and both groups showed decreased xerostomia as compared with the start of the study, but only the study group taking xylitol tablets had a significant decrease, as compared with the group taking sorbitol (23).

The difference between the work by Lapiedra et al. and the present study is that, in this study, the amount of saliva was collected and measured (both basal and stimulated) using paraffin pastilles, while in the study by Lapiedra et al., it was quantified using a questionnaire (23). Another difference between this study and the one carried out by Lapiedra et al. (23) was that in the latter, the authors administered 4 xylitol tablets per day, compared to 3 in this study.

In another study by Peres et al. (24) undertaken on 27 patients, using chewable maltose tablets resulted in increased compared with baseline measurements. Furthermore, 2 literature reviews carried out by Brosky et al. (25) and by Plemons (26) claim that chewable tablets increase salivary secretion in patients with xerostomia, thus improving their quality of life.

The present study also observed that the saliva-buffering capacity increased significantly on the final visit among patients treated with tablets, compared to those who were not treated with them. One can deduce that the tablets not only increased the amount of saliva but also improved its chemical properties and acid-neutralizing buffer capacity.

This finding corroborates the conclusions of Kharevich et al. (27), who, in a pilot study on 10 patients, also observed increased saliva-buffering capacity, which reduced its acidity and minimised xerostomia, as in this study with xylitol-malic acid tablets.

The present study also found some improvement among the patients treated with tablets with respect to bitter taste in the mouth because those who did not take the xylitol-malic acid tablets experienced bitter taste more intensely and more frequently. Note that bitter taste in the mouth is one of the most characteristic symptoms of GORD, $(28,29)$ so much so that although certain drugs objectively improve the disease's symptoms (such as proton pump inhibitors), they do not prevent patients from experiencing a bitter taste in their mouth, with this symptom persisting despite the treatment (30). For this reason, it is very important that the xylitol-malic acid tablets used in this study relieved this unpleasant extraoesophageal symptom of GORD.

Summarising the results provided by this study, xylitolmalic acid tablets (Xeros ${ }^{\circledR}$ ) demonstrated the capacity to improve quality of life in patients with GORD by reducing xerostomia, improving saliva-buffering capacity and relieving regurgitation and the sensation of gastric and retrosternal burning.

\section{References}

1. Vakil N, van Zanten SV, Kahrilas P, Dent J, Jones R. Global Consensus group. The Montreal definition and classification of gastroesophageal reflux disease: a global, evidence-based consensus paper. J Gastroenterol. 2007;45:1125-40.

2. Katelaris P, Holloway R, Talley N, Gotley D, Williams S, Dent J, et al. Gastroesophageal reflux disease in adults: Guidelines for clinicians. J Gastroenterol Hepatol. 2002;17:825-33.

3. Philip O, Katz MD. Gastroesophageal reflux disease. J Am Geriatr Soc. 1998;46:1558-65.

4. Bansal A, Kahrilas PJ. Treatment of GERD complications (Barrett's, peptic stricture) and extra-oesophageal syndromes. Best Pract Res Clin Gastroenterol. 2010;24:961-8.

5. Testoni PA, Mazzoleni G, Testoni SG. Transoral incisionless fundoplication for gastro-esophageal reflux disease: Techniques and outcomes. World J Gastrointest Pharmacol Ther. 2016;7:179-89.

6. Saleh J, Figueiredo MA, Cherubini K, Salum FG. Salivary hypofunction: an update on aetiology, diagnosis and therapeutics. Arch Oral Biol. 2015;60:242-55.

7. Orellana MF, Lagravère MO, Boychuk DG, Major PW, Flores-Mir C. Prevalence of xerostomia in population-based samples: a systematic review. J Public Health Dent. 2006;66:152-8.

8. Zhang CZ, Cheng XQ, Li JY, Zhang P, Yi P, Xu X, et al. Saliva in the diagnosis of diseases. Int J Oral Sci. 2016;8:133-7.

9. Sakamoto Y, Kato S, Sekino Y, Sakai E, Uchiyama T, Iida H, et al. Change of gastric emptying with chewing gum: evaluation using a continuous real-time C breath test (BreathID system). J Neurogastroenterol Motil. 2011;17:174-9.

10. Wilder-Smith CH, Wilder-Smith P, Kawakami-Wong H, Voronets J, Osann K, Lussi A. Quantification of dental erosions in patients with GERD using optical coherence tomography before and after double-blind, randomized treatment with esomeprazole or placebo. Am J Gastroenterol. 2009;104:2788-95.

11. Smoak BR, Koufman JA. Effects of gum chewing on pharyngeal and esophageal pH. Ann Otol Rhinol Laryngol. 2001;110:1117-9.

12. Ranjitkar S, Smales RJ, Kaidonis JA. Oral manifestations of gastroesophageal reflux disease. J Gastroenterol Hepatol. 2012;27:21-7.

13. Corrêa MC, Lerco MM, Henry MA. Study in oral cavity alterations in patients with gastroesophageal reflux disease. Arq Gastroenterol. 2008; 45:132-6.

14. Deppe H, Mücke T, Wagenpfeil S, Kesting M, Rozej A, Bajbouj $\mathrm{M}$, et al. Erosive esophageal reflux vs. non erosive esophageal reflux: oral findings in 71 patients. BMC Oral Health. 2015;15:84.

15. Di Fede O, Di Liberto C, Occhipinti G, Vigneri S, Lo Russo L, Fedele $\mathrm{S}$, et al. Oral manifestations in patients with gastro-oesophageal reflux disease: a single-center case- control study. J Oral Pathol Med. 2008;37:336-40.

16. Katunari M, Juki S, Staudt-Skaljac G, Mehuli K, Komar D. Some periodontological parameters in patients with oesophagogastric passage insufficiency. Coll Antropol. 1998; 22 Suppl:199-203.

17. Song JY, Kim HH, Cho EJ, Kim TY. The relationship between 
gastroesophageal reflux disease and chronic periodontitis. Gut Liver. 2014;8:35-40.

18. Moazzez R, Bartlett D, Anggiansah A. The effect of chewing sugar-free gum on gastro-esophageal reflux. J Dent Res. 2005; 84:1062-5.

19. Humphrey SP, Williamson RT. A review of saliva: normal composition, flow and function. J Prosthet Dent. 2001;85:162-9.

20. Esplugues JV. A pharmacological approach to gastric acid inhibition. Drugs. 2005; 65 Suppl 1:7-12.

21. Mäkinen KK. Sugar alcohol sweeteners as alternatives to sugar with special consideration of xylitol. Med Princ Pract. 2011;20:303-20. 22. Donachie MA, Walls AW. The tooth wear index: a flawed epidemiological tool in an ageing population group. Community Dent Oral Epidemiol. 1996;24:152-8.

23. Lapiedra RC, Gómez GE, Sánchez BP, Pereda AA, Turner MD. The effect of a combination saliva substitute for the management of xerostomia and hyposalivation. J Maxillofac Oral Surg. 2015;14:653-8. 24. Peres JC, Rouquette JL, Miočević O, Warner MC, Slowey PD, Shirtcliff EA. New techniques for augmenting saliva collection: bacon rules and lozenge drools. Clin Ther. 2015;37:515-22.

25. Brosky ME. The role of saliva in oral health: strategies for prevention and management of xerostomia. J Support Oncol. 2007;5:215-25. 26. Plemons JM, Al-Hashimi I, Marek CL. Managing xerostomia and salivary gland hypofunction: executive summary of a report from the American Dental Association Council on Scientific Affairs. J Am Dent Assoc. 2014;145:867-73.

27. Kharevich O, Shipman B, Goldman BM, Nahon M. Salese to buffer saliva in elderly patients with xerostomia: a pilot study. J Prosthodont. 2011;20:135-8.

28. Preetha A, Sujatha D, Patil BA, Hegde S. Oral manifestations in gastroesophageal reflux disease. Gen Dent. 2015;63:e27-31.

29. Budylina SM, Dmitrieva LA, Kostina NV, Georgieva OA, Pertsov SS. Taste perception during clinical symptom complex of gastroesophageal reflux disease. Patol Fiziol Eksp Ter. 2015;59:51-6. 30. Woodland P, Sifrim D. Management of gastro-oesophageal reflux disease symptoms that do not respond to proton pump inhibitors. Curr Opin Gastroenterol. 2013;29:431-6.

\section{Funding}

The study was funded by Dentaid S.A. (Vallés Technology Park, Barcelona, Spain).

\section{Conflict of interest}

The study was funded by Dentaid S.A. (Vallés Technology Park, Barcelona, Spain). Despite this, the authors declare no conflicts of interest.

\section{Ethics}

This study was conducted in accordance with the ethical principles for medical research on humans, as defined in the Declaration of Helsinki, and following the standards of good clinical practice. Approval was obtained from the Ethical Committee of Virgen del Rocío and Virgen Macarena Hospital before commencing the study (ERGE-2016-01). Each patient was duly informed and required a signed informed consent form to take part in the study.

\section{Authors contributions}

I.S.B. has carried out the data collection, the writing of the first draft of the article and has participated in the interpretation of the results. M.R.T., J.R.C.F. and G. M. P. have participated in the design of the study, its performance and the interpretation of the results. C.G.B., D.T.L. and M.A.S.F. They have participated in the supervision of the study, in the statistical analysis of the data, in the interpretation of the results and in the writing of the first drafts of the article. All authors have participated in the writing of the final manuscript. 